\title{
Wireless Battery-Free Generation of Electric Fields on One-Dimensional Asymmetric Au/ZnO Nanorods for Enhanced Raman Sensing
}

Jing Xu, ${ }^{\dagger}$ Haoxuan He, ${ }^{\dagger}$ Xiaoxia Jian, ${ }^{\dagger}$ Kuanzhi Qu,${ }^{\dagger}$ Jingwen $\mathrm{Xu},{ }^{\dagger}$ Chaowei Li, ${ }^{\dagger}$ Zhida Gao, ${ }^{\dagger}$ Yan-Yan Song ${ }^{\dagger} *$

College of Sciences, Northeastern University, Shenyang 110004, China

*E-mail: yysong@mail.neu.edu.cn.

\section{Table of Contents}

$\begin{array}{lr}\text { 1. Materials and Reagents } & \text { S3 }\end{array}$

2. Apparatus and Characterization S3

$\begin{array}{ll}\text { 3. Preparation of } \mathrm{TiO}_{2} \text { NTs } & \text { S3 }\end{array}$

$\begin{array}{ll}\text { 4. FDTD simulation. } & \text { S3 }\end{array}$

Figure S1. Schematic of the SERS performance induced by piezotronic effect. S5

Figure S2. Top-view SEM image of ZnO NRs. S6

Figure S3. SEM of the $\mathrm{Au} / \mathrm{ZnO}$ NRs with different sputtering time. $\quad$ S7

Figure S4. SEM image of the side view of the Au/ZnO NRs. S8

$\begin{array}{ll}\text { Figure S5. HAADF-STEM image of Au/ZnO NRs. } & \text { S9 }\end{array}$

$\begin{array}{lr}\text { Figure S6. Raman spectra of } \mathrm{Au} / \mathrm{ZnO} \text { NRs. } & \text { S10 }\end{array}$ 
Figure S7. UV/Visible diffuse reflectance spectra of $\mathrm{Au} / \mathrm{ZnO}$ NRs.

Figure S8. SERS spectra of 4-MPBA under different AuNPs sputtering time. $\quad$ S12

Figure S9. Digital photos of the instrument for force measurement. $\quad$ S13

Table S1. The force between magnets with different MF density. S13

Figure S10. SERS and E-SERS spectra of R6G and 4-MPBA on Au/ZnO NRs. S14

Figure S11. SERS and E-SERS spectra of R6G and 4-MPBA on Au NPs. $\quad$ S15

Figure S12. SERS and E-SERS spectra of R6G and 4-MPBA on ZnO NRs. $\quad$ S16

Figure S13. SERS and E-SERS spectra of R6G and 4-MPBA on $\mathrm{TiO}_{2} \mathrm{NTs} \quad \mathrm{S} 17$

Figure S14. SERS and E-SERS spectra of R6G and 4-MPBA on $\mathrm{Au} / \mathrm{TiO}_{2}$ NTs. $\quad \mathrm{S} 18$

Figure S15. Raman spectrum of 4-MPBA on different substrates. $\quad$ S19

Figure S16. SERS and E-SERS spectra of 4-MPBA on AuNPs and Au/ZnO NRs. S20

$\begin{array}{ll}\text { Figure S17. Electromagnetic field intensity distribution. } & \text { S21 }\end{array}$

Figure S18. Simulation of the LSPR field at the interface of $\mathrm{Au} / \mathrm{ZnO}$ NRs. $\quad$ S22

$\begin{array}{ll}\text { Figure S19. Zeta potential of } \mathrm{Au} / \mathrm{ZnO} \text { NRs. } & \text { S23 }\end{array}$

Figure S20. Raman spectra of $\mathrm{PB}$ at different $\mathrm{K}_{3}\left[\mathrm{Fe}(\mathrm{CN})_{6}\right]$ concentration. S24

$\begin{array}{ll}\text { Figure S21. SEM image of PB at different reaction times. } & \text { S25 }\end{array}$

Figure S22. Elemental mapping images of $\mathrm{PB}$ on $\mathrm{Au} / \mathrm{ZnO}$ NRs. $\quad$ S26

Figure S23. UV/Visible diffuse reflectance spectra of PB on $\mathrm{Au} / \mathrm{ZnO}$ NRs. $\quad$ S27

$\begin{array}{ll}\text { Figure S24. Raman spectra of lactate. } & \text { S28 }\end{array}$

$\begin{array}{ll}\text { Figure S25. E-SERS spectra of lactate under different bending angles. } & \text { S29 }\end{array}$

$\begin{array}{ll}\text { Table S2. Raman intensity at } 1091 \mathrm{~cm}^{-1} \text { under different bending angles. } & \text { S29 }\end{array}$

Figure S26. Uniformity of E-SERS signal on one $\mathrm{Au} / \mathrm{ZnO}$ substrate. $\quad \mathrm{S} 30$

$\begin{array}{ll}\text { Figure S27. Reproducibility of } \mathrm{Au} / \mathrm{ZnO} \text { NRs. } & \text { S31 }\end{array}$

Figure S28. E-SERS spectra of lactate in sweat of female volunteers exercise. S32

Figure S29. E-SERS spectra of lactate in sweat of male volunteers exercise. S33

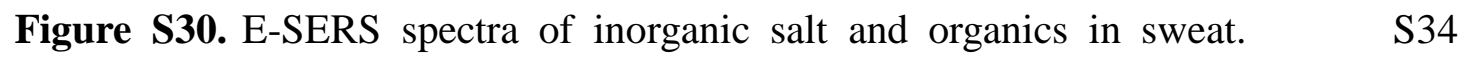

$\begin{array}{ll}\text { Figure S31. Raman spectra of thiram. } & \text { S35 }\end{array}$

$\begin{array}{ll}\text { Figure S32. Raman standard curve of thiram. } & \text { S36 }\end{array}$

Figure S33. E-SERS spectra of thiram from the surfaces of apples and cucumbers.S37

$\begin{array}{ll}\text { Reference } & \text { S38 }\end{array}$ 


\section{Materials and Reagents}

Titanium sheets $(\sim 150 \mu \mathrm{m}$ thickness, purity $99.7 \%)$ were purchased from Sigma-Aldrich (Germany). Ethyl alcohol $\left(\mathrm{C}_{2} \mathrm{H}_{5} \mathrm{OH}\right)$, isopropanol $\left(\mathrm{C}_{3} \mathrm{H}_{8} \mathrm{O}\right)$, ammonium hydroxide $\left(\mathrm{NH}_{3} \cdot \mathrm{H}_{2} \mathrm{O}\right.$, purity 25\%-28\%), zinc acetate dihydrate $\left(\mathrm{Zn}\left(\mathrm{CH}_{3} \mathrm{COO}\right)_{2} \cdot 2 \mathrm{H}_{2} \mathrm{O}\right)$, zinc nitrate hexahydrate $\left(\mathrm{Zn}\left(\mathrm{NO}_{3}\right)_{2} \cdot 6 \mathrm{H}_{2} \mathrm{O}\right)$, ammonium fluoride $\left(\mathrm{NH}_{4} \mathrm{~F}\right)$, ethylene glycol, potassium ferricyanide $\left(\mathrm{K}_{3}\left[\mathrm{Fe}(\mathrm{CN})_{6}\right]\right)$, lactate $\left(\mathrm{C}_{3} \mathrm{H}_{6} \mathrm{O}_{3}\right)$ were purchased from Sinopharm Chemical Reagent Co., Ltd.(Shanghai, China). Ferric chloride $\left(\mathrm{FeCl}_{3}\right)$, thiram $\left(\mathrm{C}_{6} \mathrm{H}_{12} \mathrm{~N}_{2} \mathrm{~S}_{4}\right)$, Rhodamine $6 \mathrm{G}\left(\mathrm{C}_{28} \mathrm{H}_{30} \mathrm{~N}_{2} \mathrm{O}_{3}\right)$, 4-mercaptophenylboronic acid (4-MPBA, purity > 90\%) were purchased from Sigma-Aldrich (St. Louis, MO, U.S.A.).

\section{Apparatus and Characterization}

SERS measurements were conducted using a Raman microscopy spectrometer (LabRAM HR, HORIBA Scientific, France). Morphologies and microstructures of the prepared samples were carried out by a field-emission scanning electron microscope (FESEM SU 8000, Japan). The TEM and HRTEM images of the materials was characterized using a high-resolution transmission electron microscope (JEOL 2000FX, Japan). X-ray diffraction (XRD) patterns were acquired using an X'Pert XRD spectrometer (Philips, USA) equipped with a $\mathrm{CuK} \alpha \mathrm{X}$-ray source. UV/visible diffuse reflectance spectra was obtained using a Perkin-Elmer spectrometer (Lambda 750S, USA). Zeta potential was measured using a nano zetasizer (Nano zs90 Malvin Instruments, USA).

\section{Preparation of $\mathrm{TiO}_{2} \mathrm{NTs}$}

$\mathrm{TiO}_{2}$ NTs were grown on $\mathrm{Ti}$ substrates by electrochemical anodization. Ti substrates $(15 \mathrm{~mm} \times 15 \mathrm{~mm} \times 150 \mu \mathrm{m})$ were first ultrasonically cleaned in isopropanol, ethanol, and deionized water in sequence, and dried with $\mathrm{N}_{2}$ stream. Then, $\mathrm{TiO}_{2} \mathrm{NTs}$ were fabricated by the anodization of $\mathrm{Ti}$ sheets at $60 \mathrm{~V}$ for $30 \mathrm{~min}$ in ethylene glycol/water electrolyte containing $0.15 \mathrm{M} \mathrm{NH}_{4} \mathrm{~F}$. Ti sheet and platinum foil were used as the working electrode and counter electrode, respectively.

\section{FDTD simulation.}

The dielectric constant of the gold nanoparticle (Au NP) was calculated using 
Drude-Lorentz dispersion model, according to Formula (S1):

$\varepsilon(\omega)=\omega_{\infty}-\frac{\omega^{2} p}{\omega^{2}-\omega \gamma i}-\frac{f \Omega^{2} L}{\omega^{2}-\Omega^{2}{ }^{2}+\omega r_{L} i}$

The parameters in the equation are the same as in previous study, ${ }^{\mathrm{S}-\mathrm{S} 3}$ with the frequency independent dielectric constant $\varepsilon_{\infty}=6.2137$, plasma frequency $\omega_{P}=1.3323 e+16 \mathrm{rad} \mathrm{S}^{-1}$, damping constant $\gamma=1.3235 \mathrm{e}+14 \mathrm{rad} \mathrm{S}^{-1}$, Lorentz weighting factor $\mathrm{f}=3.4620$, damping constant of the Lorentz oscillator $r_{L}=2.1367 e+15 \mathrm{radS}^{-1}$, and Lorentz oscillator strength $\Omega_{L}=4.7914 e+$ $15 \mathrm{rad} \mathrm{S}^{-1}$. The effect of change in electron density was calculated using the modified equation, where only $\omega_{P}$ and $\Omega_{L}$ are dependent on the electron density of Au. An equal amount of electrons $\Delta N /{ }_{N}$ should be added to both the Drude-free electron part and the Lorentz oscillation part so that $\omega_{p}(f)^{2}=\omega_{p}(i)^{2}\left(1+\frac{\Delta N}{N}\right)$ and $\Omega_{L}(f)^{2}=\Omega_{L}(i)^{2}\left(1+\frac{\Delta N}{N}\right)$ where $\omega_{p}(f)$ and $\Omega_{L}(f)$ denote the corresponding values corrected using the Lorentz weighting function, and $\omega_{p}(i)$ and $\Omega_{L}(i)$ represent the eigen values (under $0 \mathrm{~V}$ ).

FDTD simulations were performed using FDTD Solutions 2018a. An electromagnetic pulse fixed at $638 \mathrm{~nm}$ for the incident light was launched into a box containing the target $\mathrm{Au}$ nanostructure to simulate a propagating plane wave interacting with the nanostructure. The overlap region of $\mathrm{Au} \mathrm{NP}$ was divided into $0.2 \mathrm{~nm}$ meshes. The refractive index of the surrounding medium was taken as 1.0. The Au NP was modeled as a sphere with $10 \mathrm{~nm}$ diameter according to the SEM measurements. 


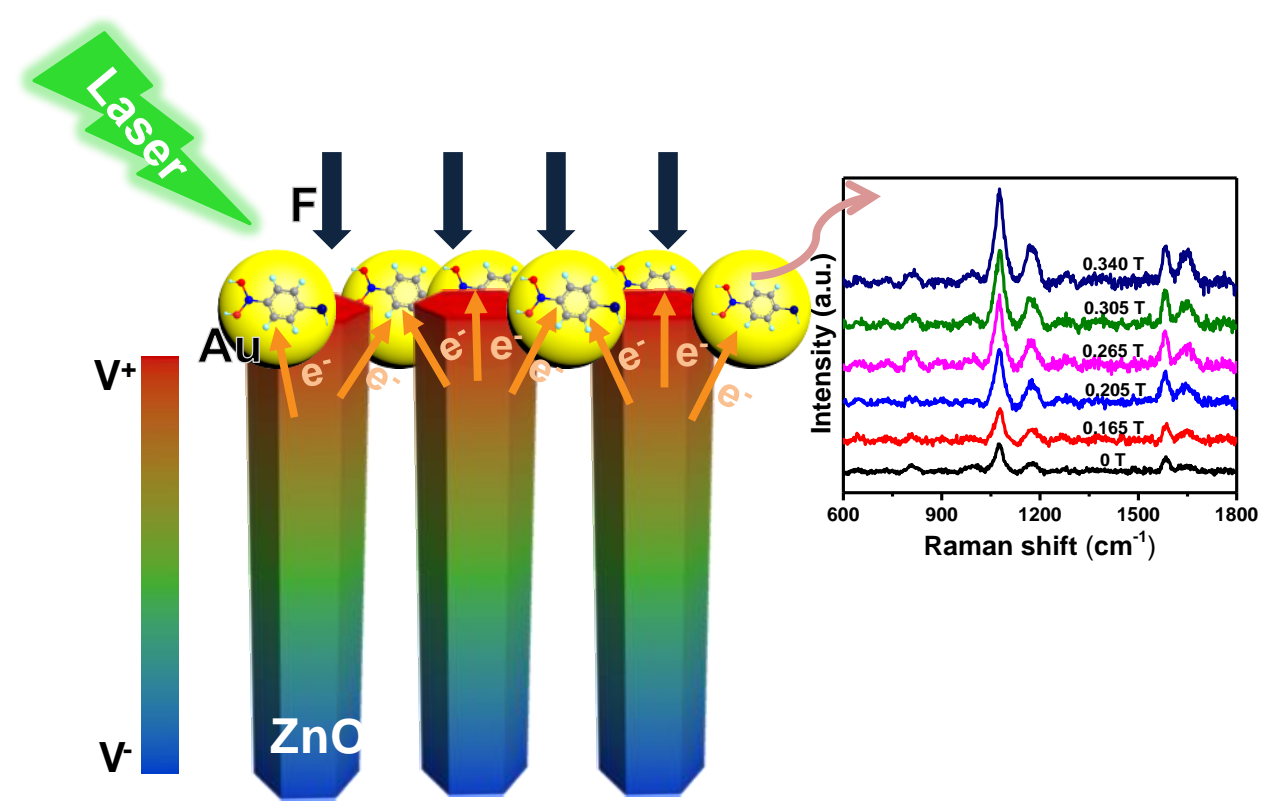

Figure S1. Schematic illustration of the SERS mechanism induced by piezotronic effect.

When a force is applied in the direction parallel to the aligned $\mathrm{ZnO} \mathrm{NRs}$, the centers of mass for positive and negative ions are shifted, resulting in a net dipole moment (polarization) along this direction. In general, charges are formed in the bent NRs via the polarization generated by the ionic charges of lattice ions along the width. Owing to the asymmetric structured $\mathrm{Au} / \mathrm{ZnO} \mathrm{NRs}$, the charges generated by piezoelectric effect can be effectively separated, thus generating a high potential along the c-axis under axial stress. The density of free electron at the metal/dielectric interface increases, which in turn greatly enhanced the local electromagnetic field and generates the E-SERS process. ${ }^{\mathrm{S3}, \mathrm{S} 4}$ 


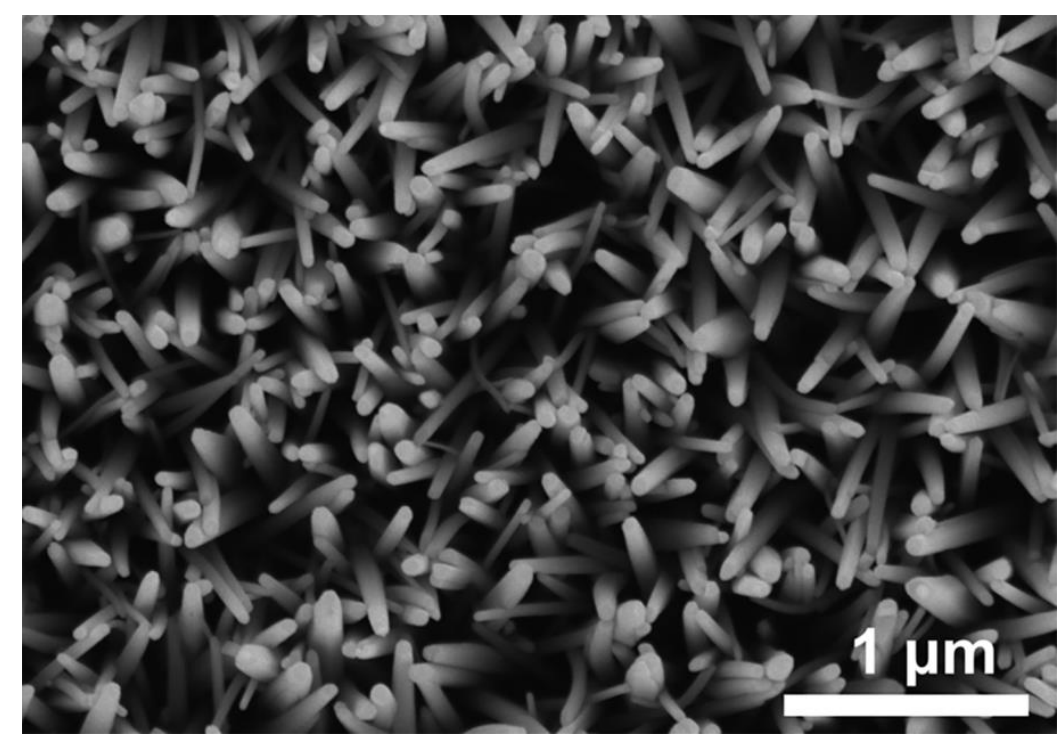

Figure S2. Top-view SEM image of ZnO NRs. 

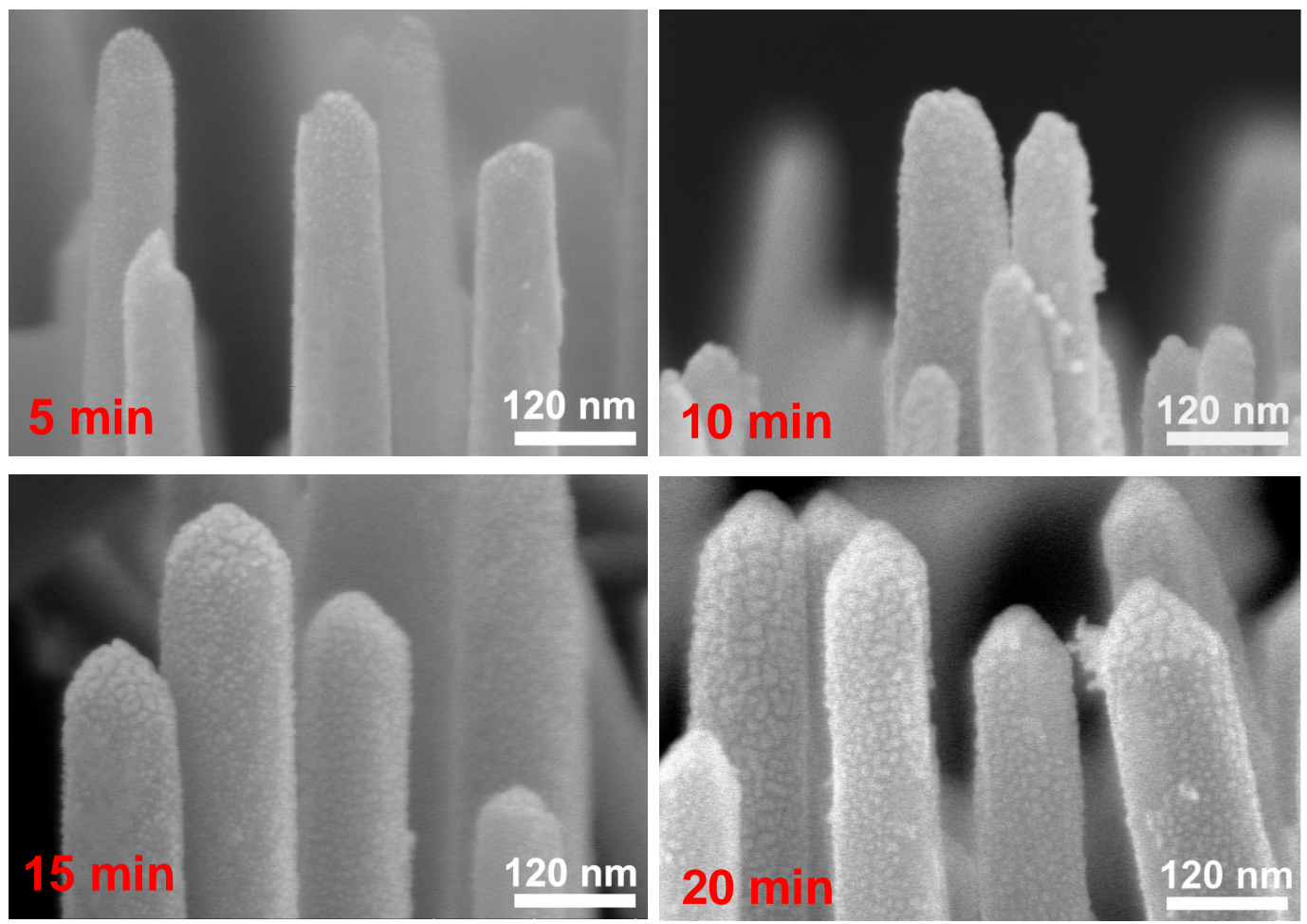

Figure S3. SEM image of the side view of $\mathrm{Au} / \mathrm{ZnO}$ NRs at different Au sputtering times. 


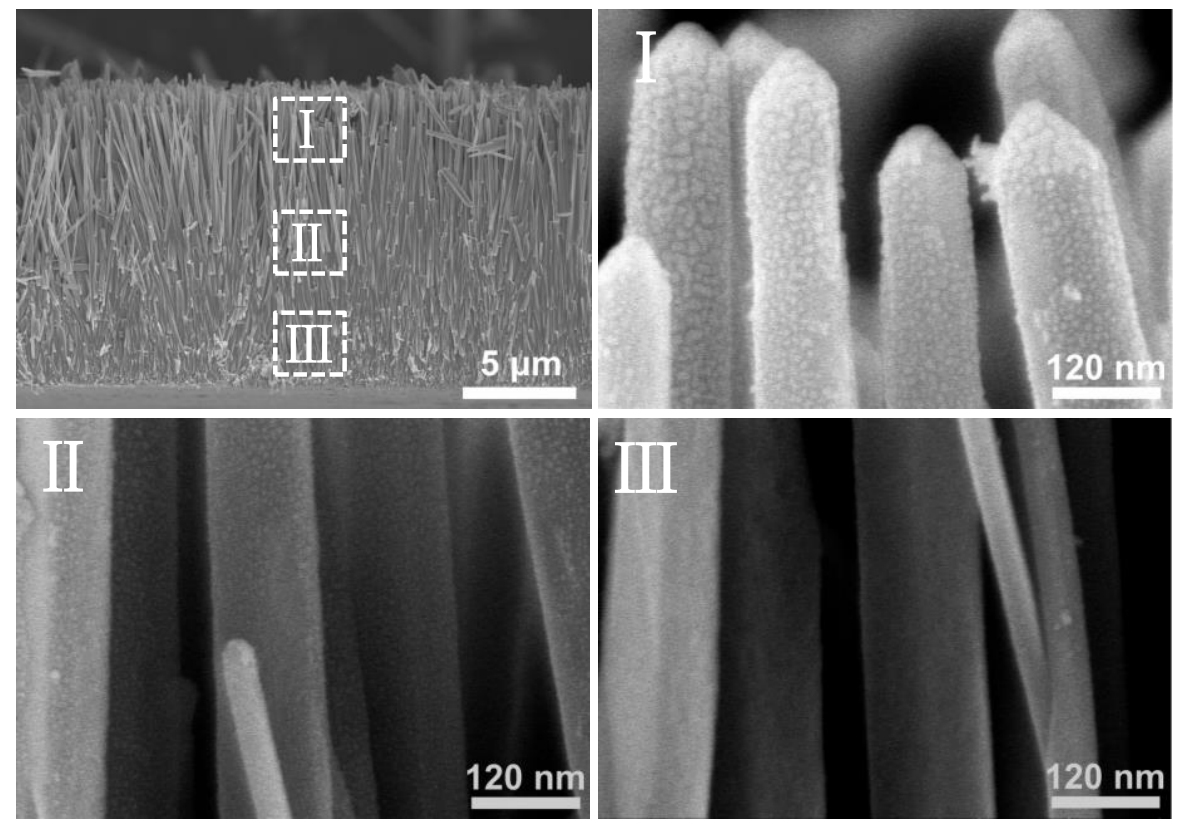

Figure S4. SEM images of different positions on the cross-section of Au/ZnO NRs at (I) top, (II) middle, and (III) bottom part. 


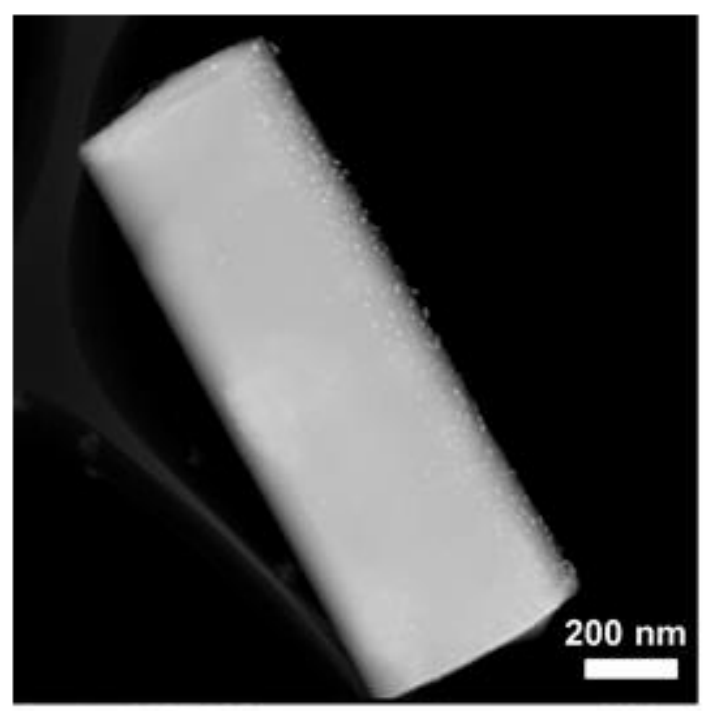

Figure S5. HAADF-STEM image of Au/ZnO NRs. 


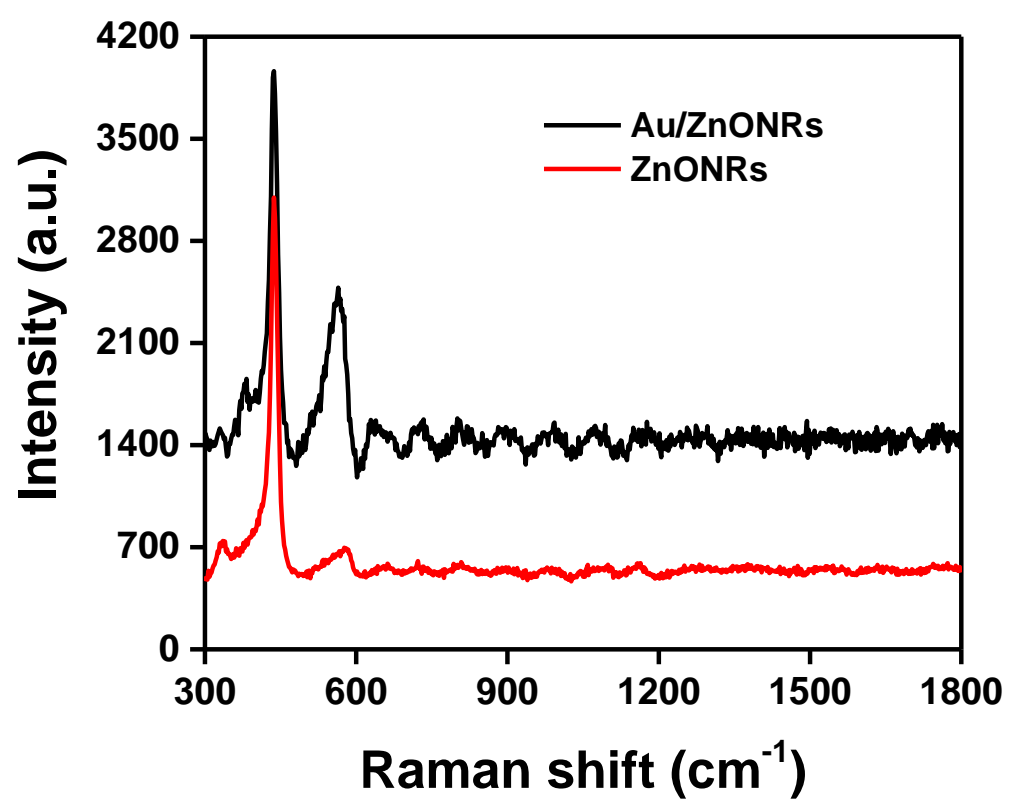

Figure S6. Raman spectra of $\mathrm{ZnO}$ and $\mathrm{Au} / \mathrm{ZnO}$ NRs. 


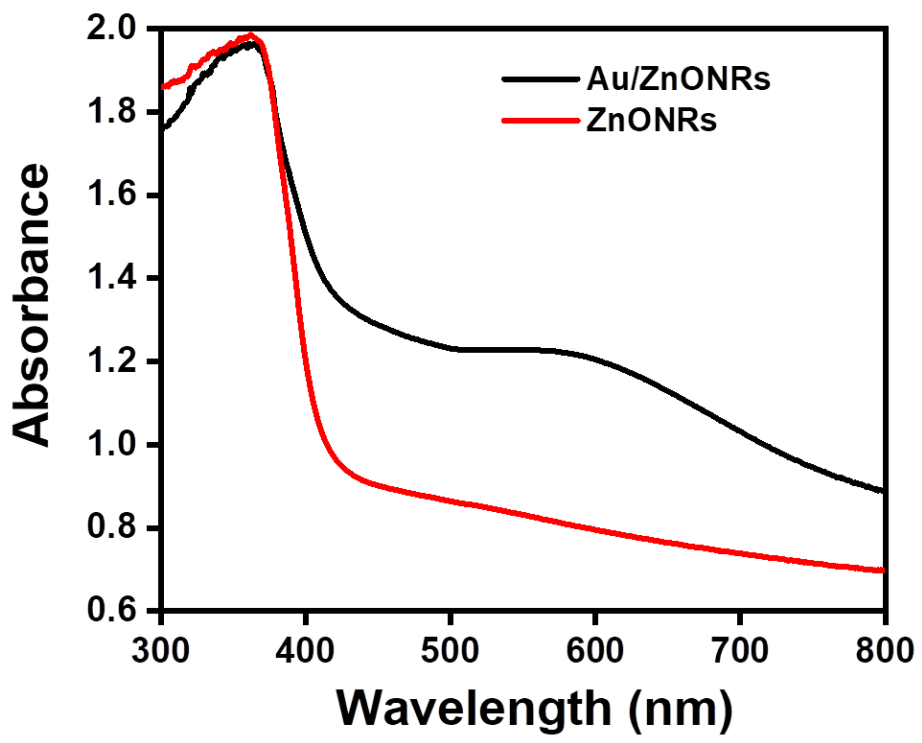

Figure S7. UV/Visible diffuse reflectance spectra of $\mathrm{ZnO}$ and $\mathrm{Au} / \mathrm{ZnO} \mathrm{NR}$ array. 


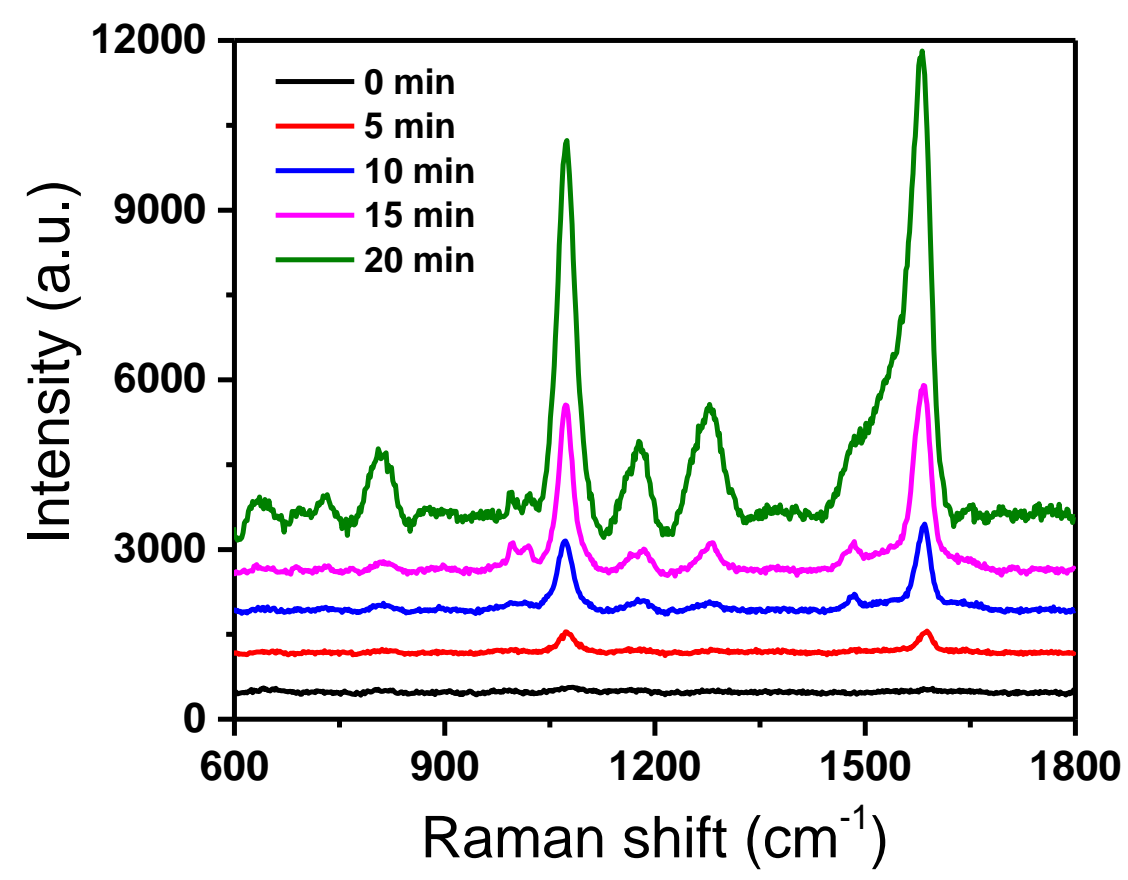

Figure S8. SERS spectra of 4-MPBA at different Au sputtering times. 


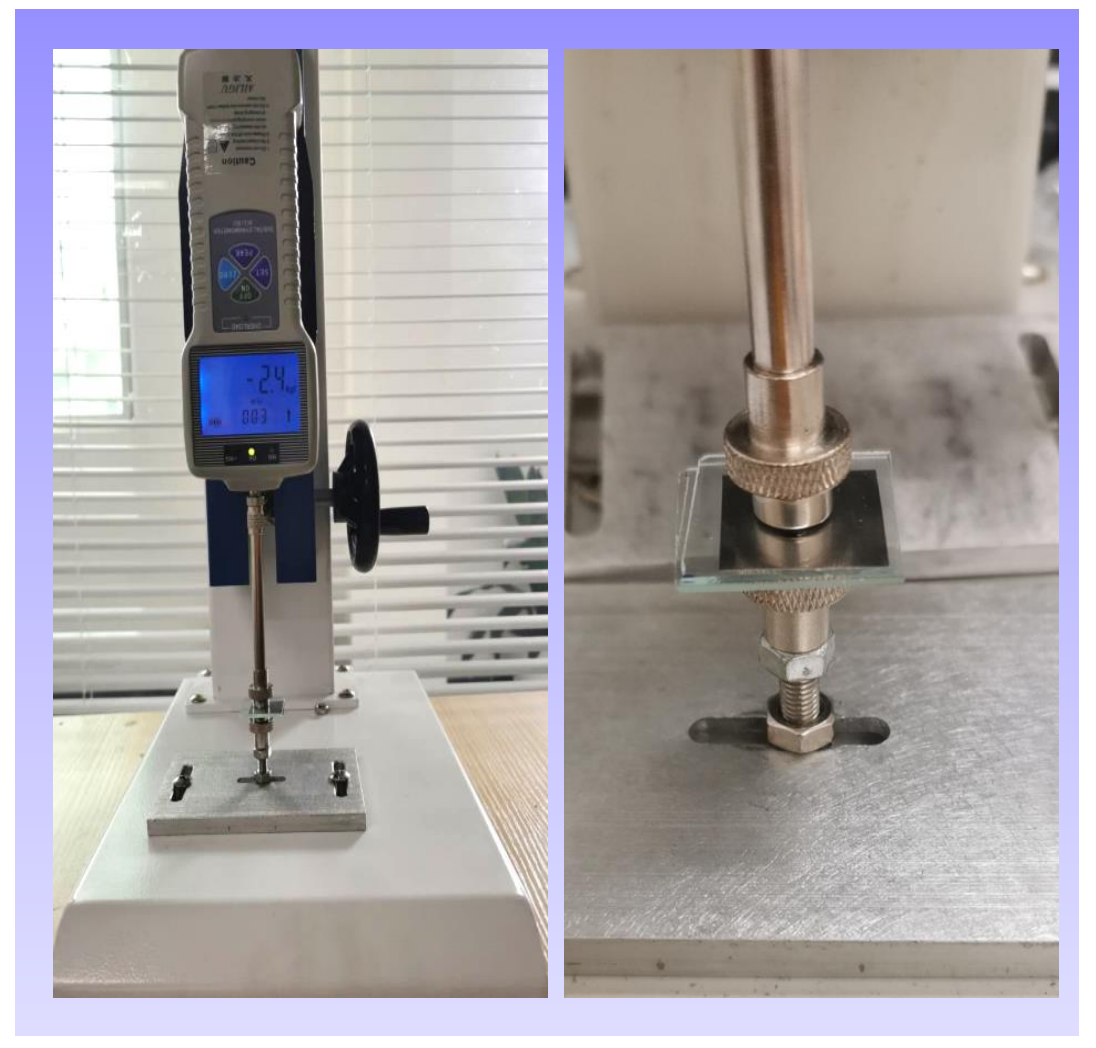

Figure S9. The instrument used for force measurement.

Table S1. The force between magnets with different MF densities.

\begin{tabular}{|c|c|c|c|c|c|}
\hline MF density (T) & 0.165 & 0.205 & 0.265 & 0.305 & 0.340 \\
\hline Force $(\mathrm{N})$ & 84.8 & 88.8 & 106 & 110 & 119.6 \\
\hline
\end{tabular}



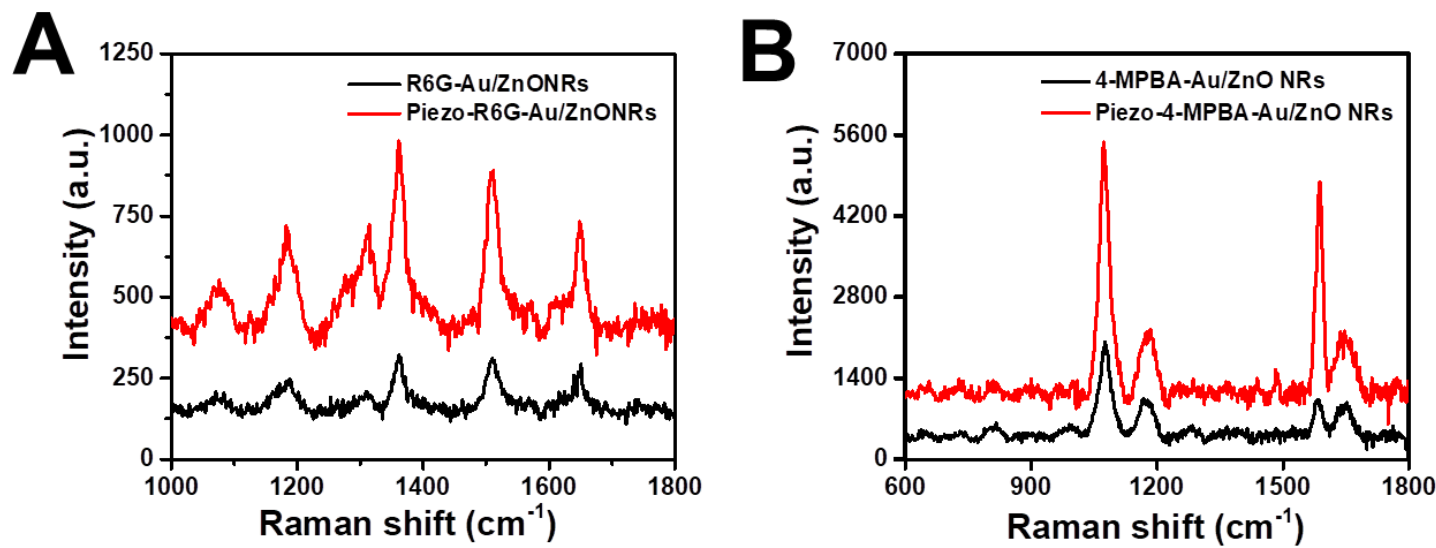

Figure S10. SERS and E-SERS spectra of R6G (A) and 4-MPBA (B) on Au/ZnO NR substrate. 

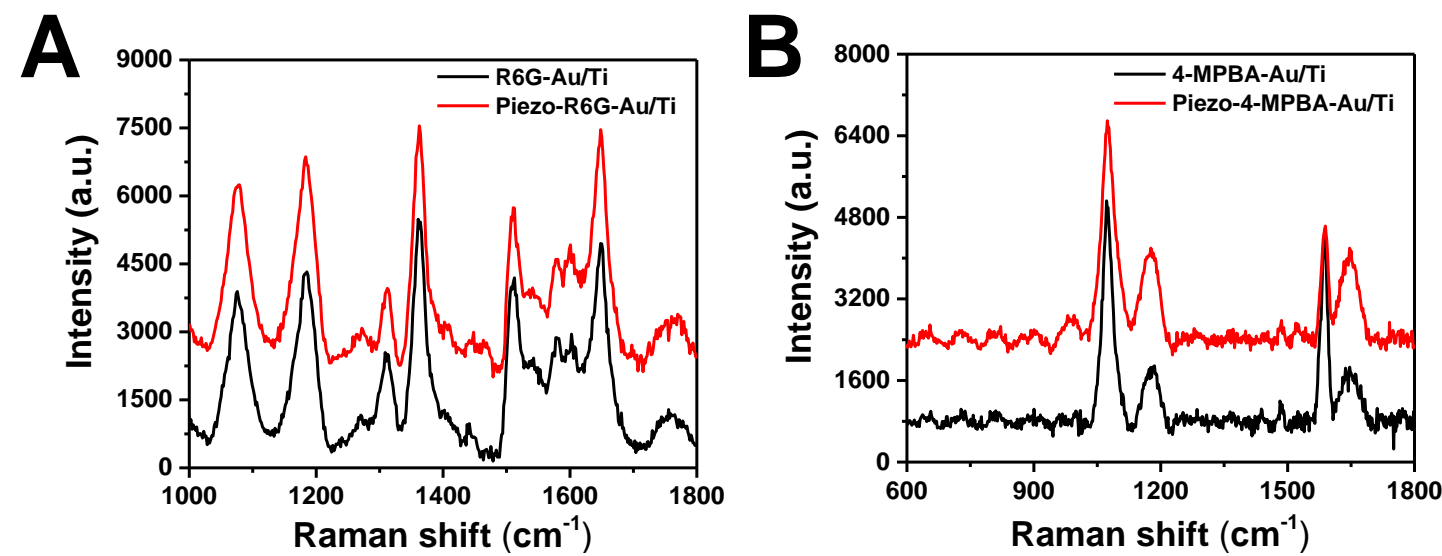

Figure S11. SERS and E-SERS spectra of R6G (A) and 4-MPBA (B) on Au NP substrate. 

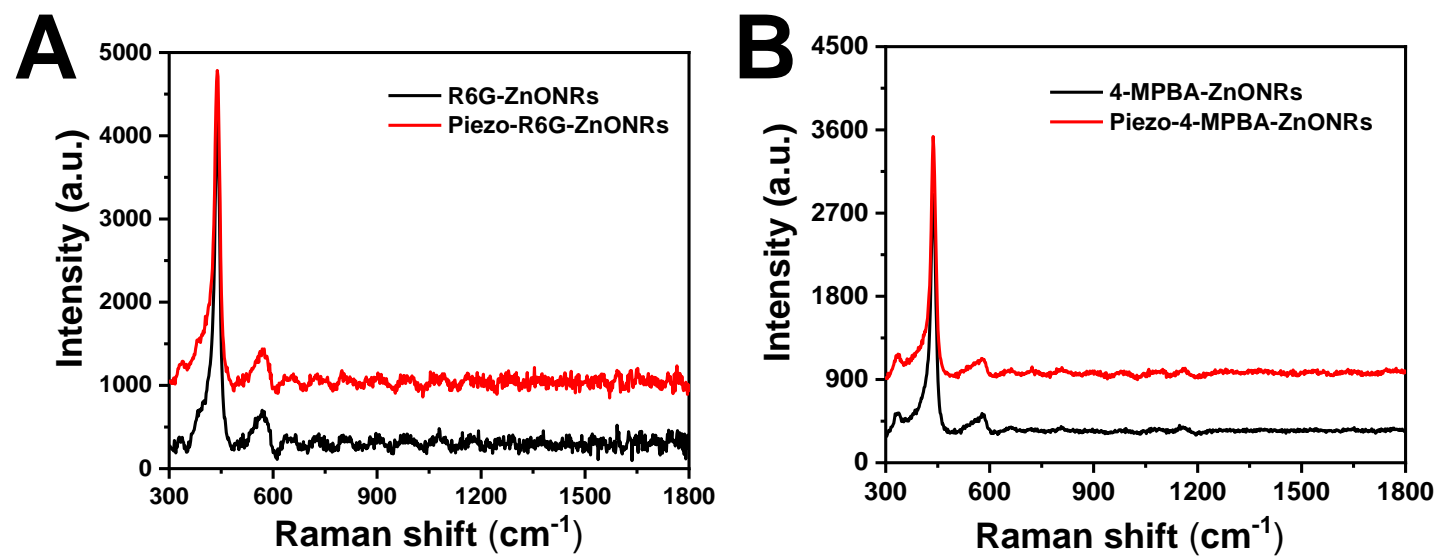

Figure S12. SERS and E-SERS spectra of (A) R6G and (B) 4-MPBA on ZnO NRs. 

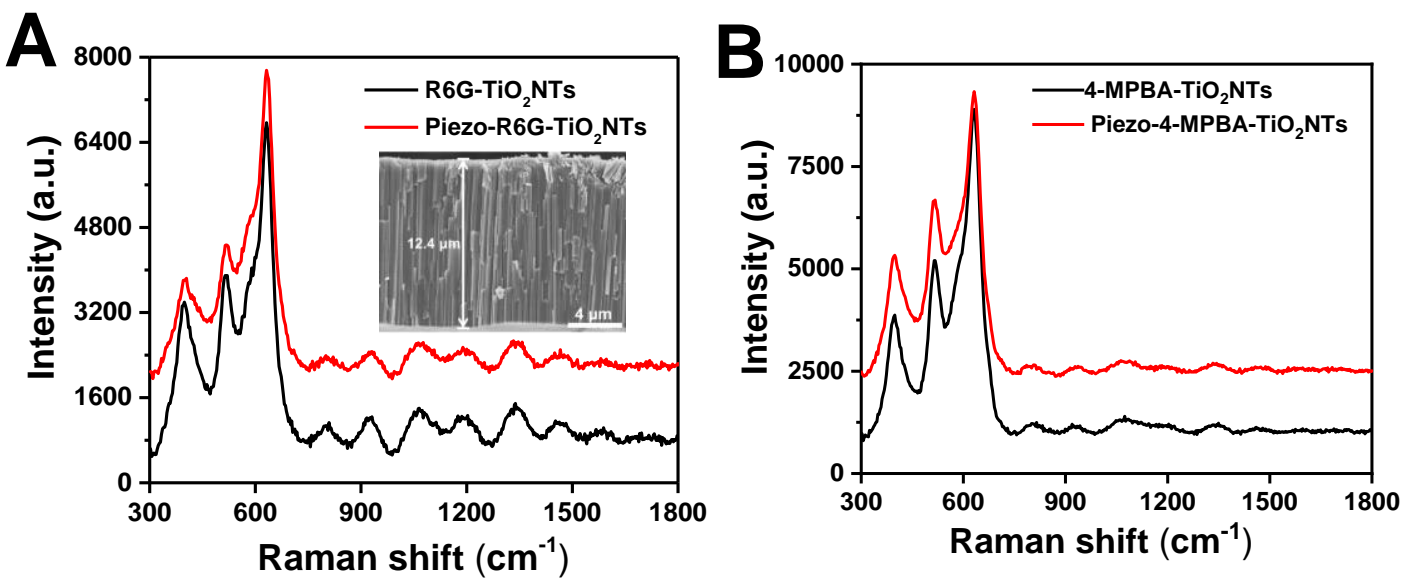

Figure S13. SERS and E-SERS spectra of (A) R6G and (B) 4-MPBA on $\mathrm{TiO}_{2} \mathrm{NTs}$ Inset: SEM image of the side view of $\mathrm{TiO}_{2}$ NTs. 

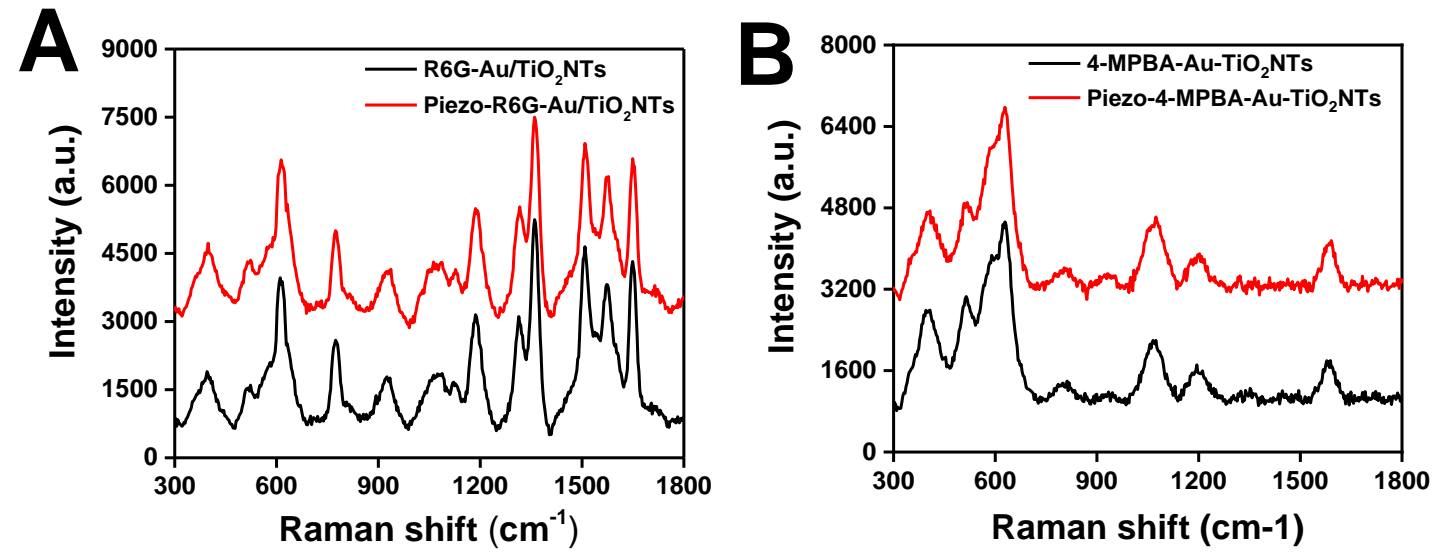

Figure S14. SERS and E-SERS spectra of (A) R6G and (B) 4-MPBA on $\mathrm{Au} / \mathrm{TiO}_{2}$ NTs. 


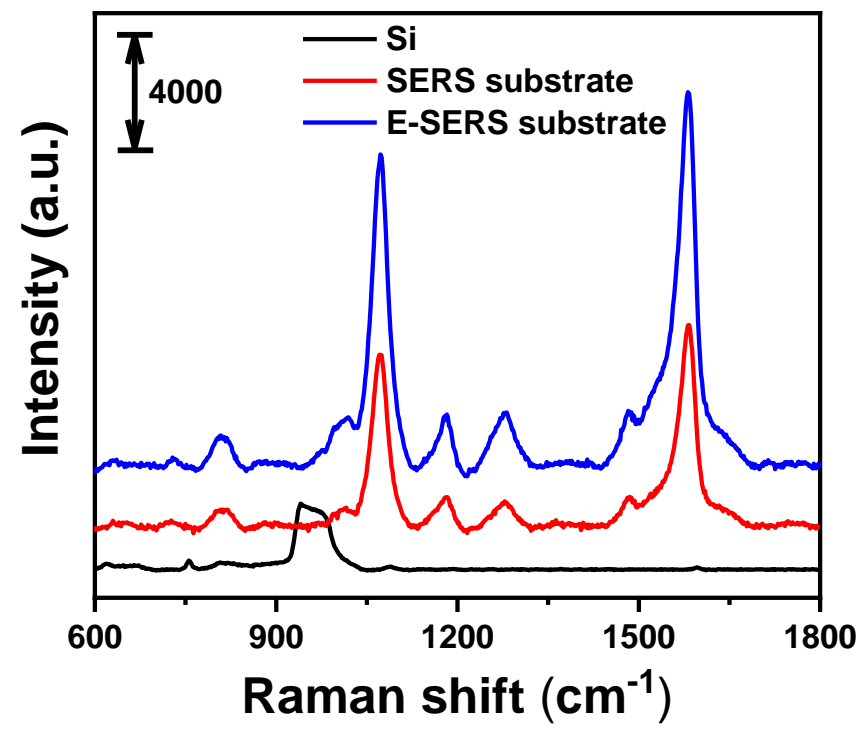

Figure S15. Raman spectra of 4-MPBA on different substrates: silicon wafer and $\mathrm{Au} / \mathrm{ZnO} \mathrm{NRs}$ with and without piezoelectric effect. 


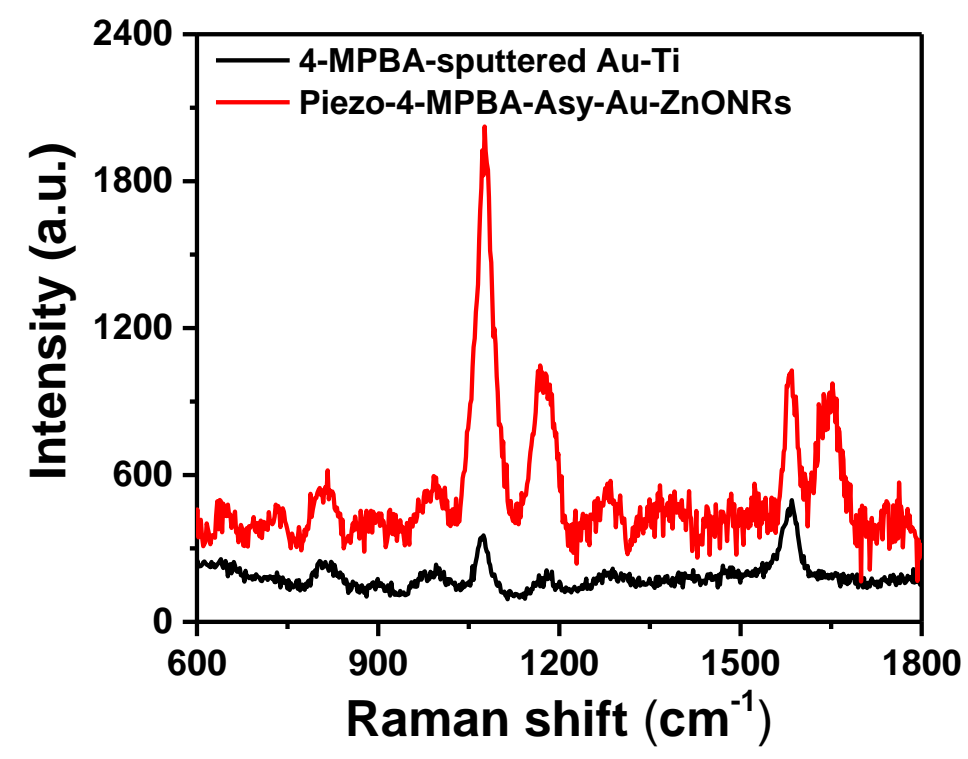

Figure S16. SERS spectra of 4-MPBA on $\mathrm{Au}$ NPs and $\mathrm{Au} / \mathrm{ZnO}$ NRs under piezoelectric effect via press from $0.340 \mathrm{~T}$ MF. 

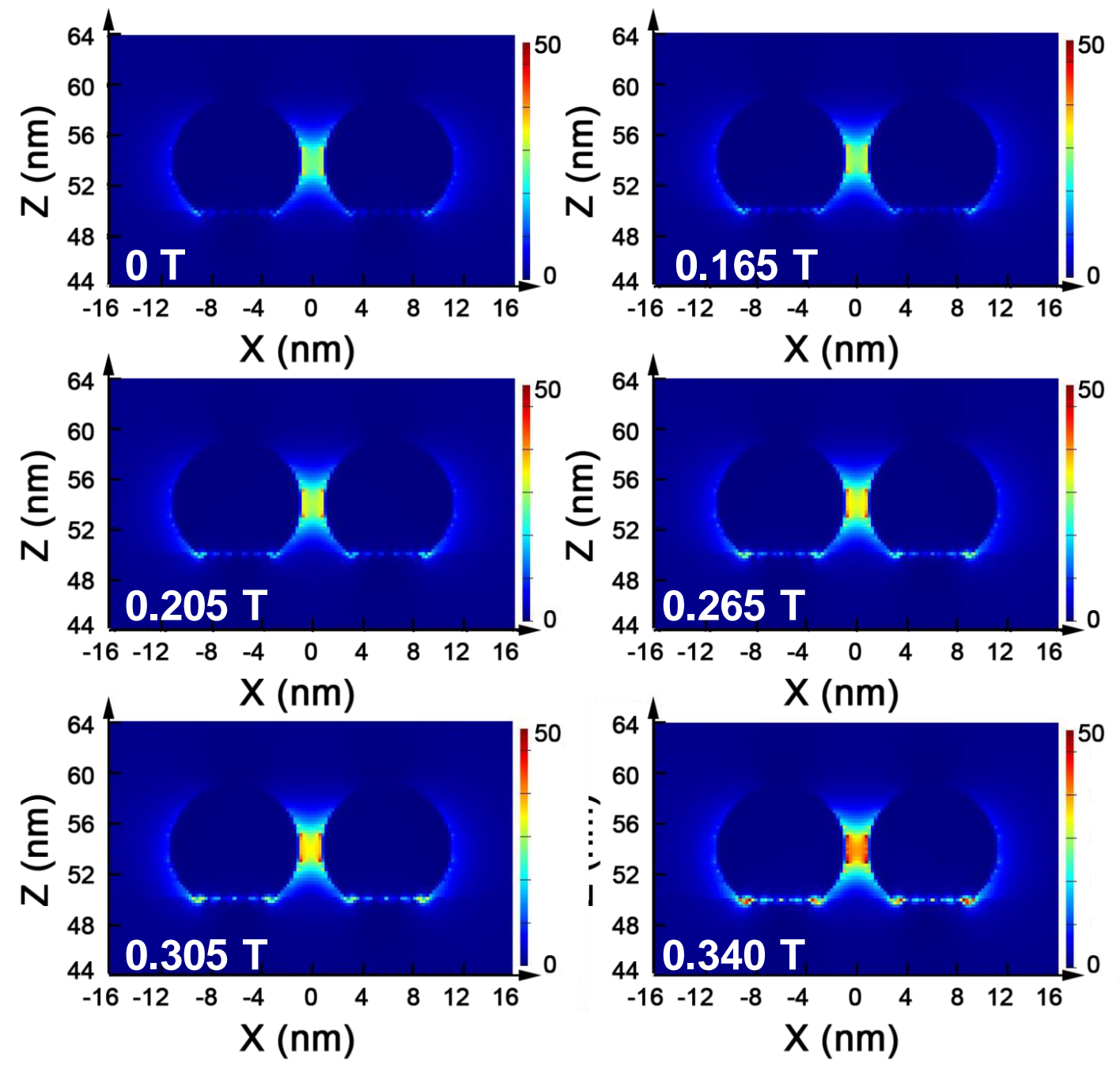

Figure S17. Electromagnetic field intensity distribution in the monitor window around the hotspot when applying different MF densities from 0 to $0.340 \mathrm{~T}$. 

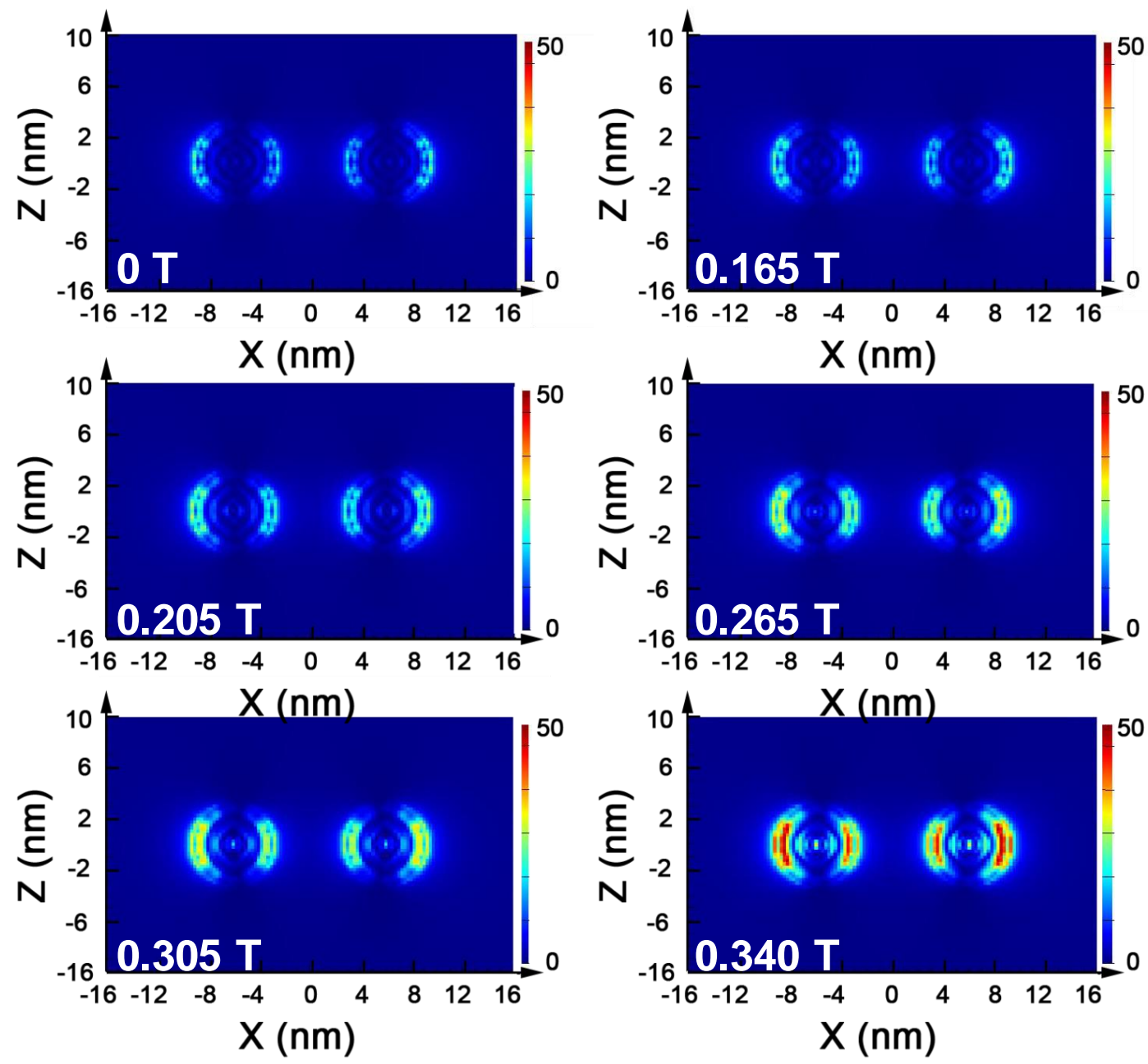

Figure S18. Simulation of the LSPR field at the interface between Au NPs and ZnO NRs when applying different MF densities from 0 to $0.340 \mathrm{~T}$. 


\begin{tabular}{|c|c|c|c|c|}
\hline \multicolumn{5}{|l|}{ Results } \\
\hline & & Mean $(\mathrm{mV})$ & Area $(\%)$ & St Dev (mV) \\
\hline Zeta Potential $(\mathrm{mV}):-30.0$ & Peak 1: & -30.0 & 100.0 & 5.68 \\
\hline Zeta Deviation $(\mathrm{mV}): 5.68$ & Peak 2: & 0.00 & 0.0 & 0.00 \\
\hline Conductivity (mS/cm): 0.00755 & Peak 3: & 0.00 & 0.0 & 0.00 \\
\hline Result quality Good & & & & \\
\hline
\end{tabular}

Zeta Potential Distribution

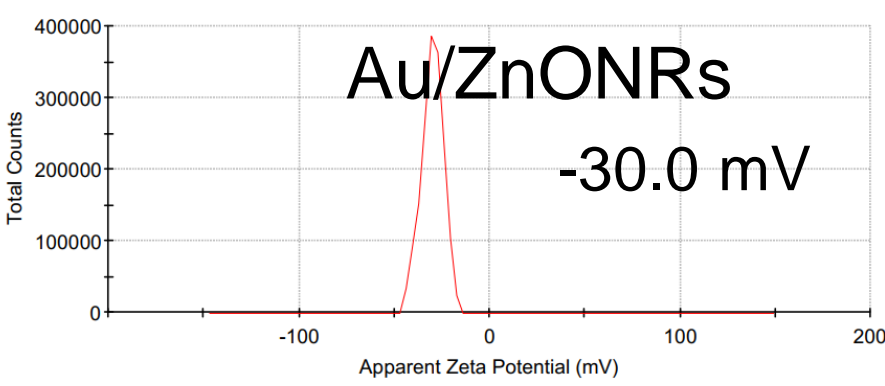

Figure S19. Zeta potential of $\mathrm{Au} / \mathrm{ZnO}$ NRs. 
A

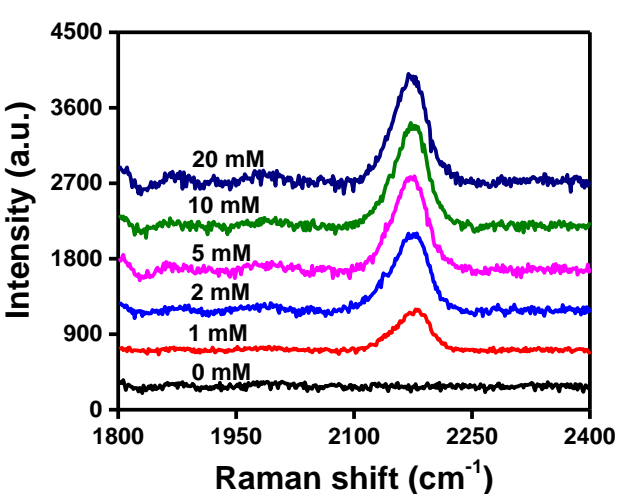

B

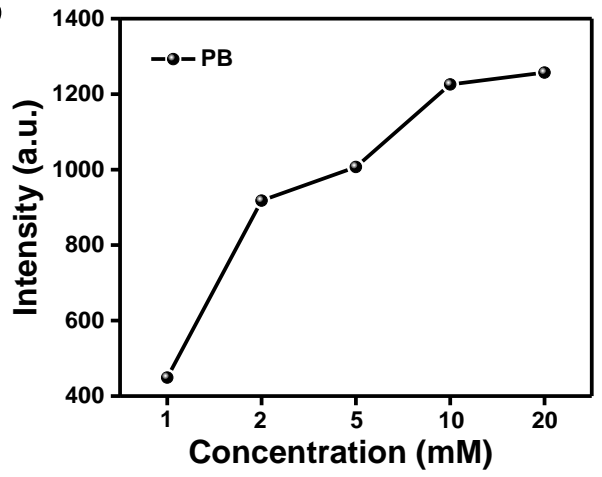

Figure S20. (A) Raman spectra of $\mathrm{PB}$ on $\mathrm{Au} / \mathrm{ZnO} \mathrm{NRs}$ at different $\mathrm{K}_{3}\left[\mathrm{Fe}(\mathrm{CN})_{6}\right]$ concentration. (B) The intensity change of Raman signal at $2183 \mathrm{~cm}^{-1}$ under different concentrations of $\mathrm{K}_{3}\left[\mathrm{Fe}(\mathrm{CN})_{6}\right]$. 


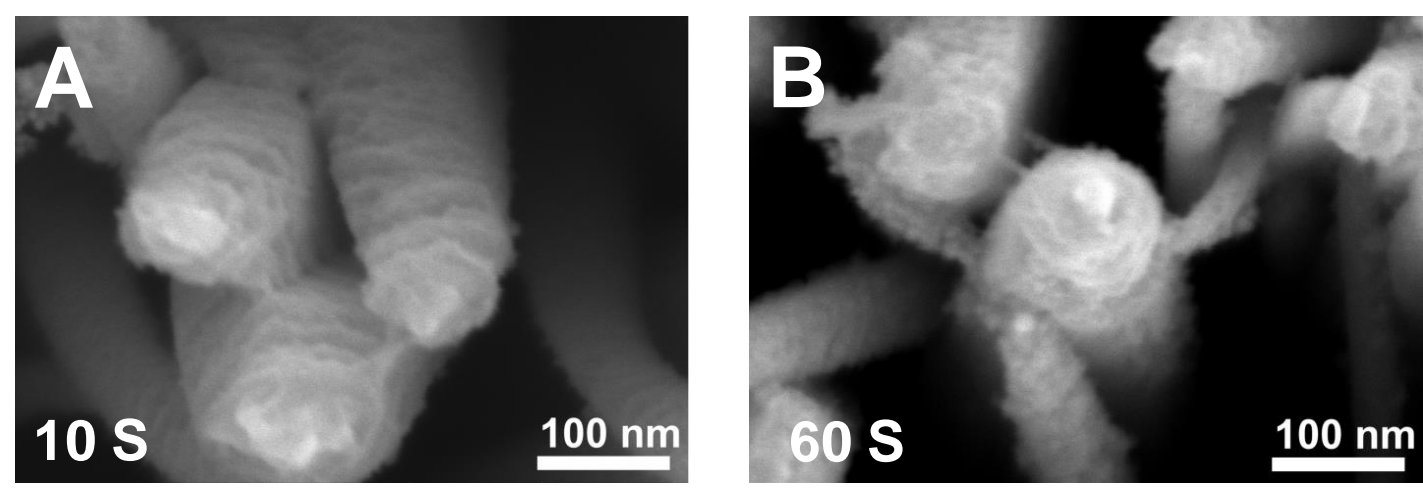

Figure S21. SEM images of PB generated on $\mathrm{Au} / \mathrm{ZnO} \mathrm{NRs}$ by pressing $10 \mathrm{~s}$ and $60 \mathrm{~s}$ under a MF density of $0.340 \mathrm{~T}$. 

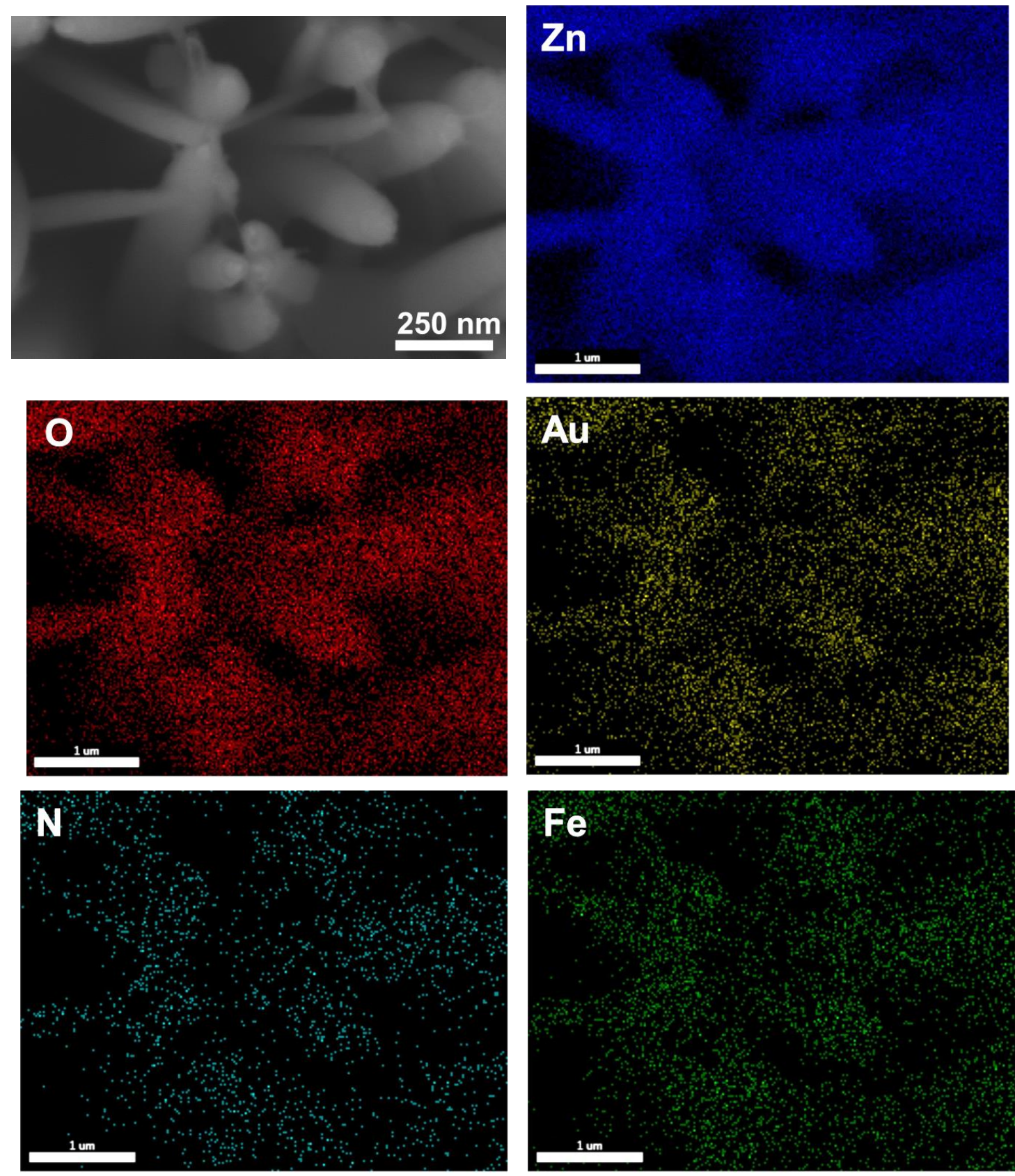

Figure S22. SEM image and the corresponding EDS mapping images of PB generated on $\mathrm{Au} / \mathrm{ZnO} \mathrm{NRs}$ by pressing $60 \mathrm{~s}$ under a MF density of $0.340 \mathrm{~T}$. 


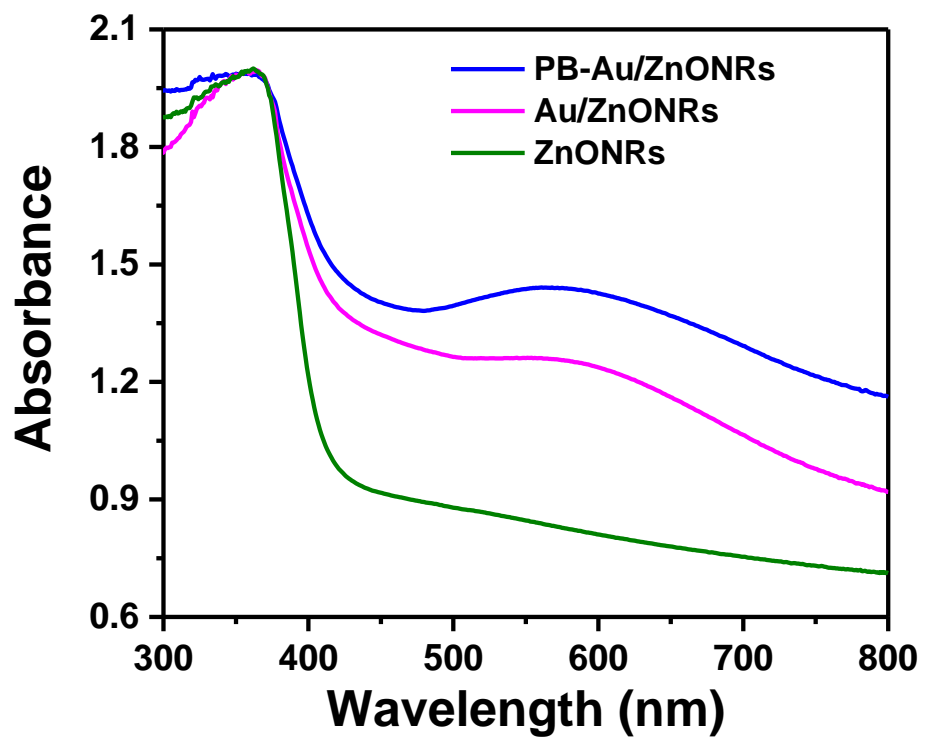

Figure S23. UV/Visible diffuse reflectance spectra of $\mathrm{ZnO} \mathrm{NRs}, \mathrm{Au} / \mathrm{ZnO} \mathrm{NRs}$, and PB coated $\mathrm{Au} / \mathrm{ZnO}$ NRs. 


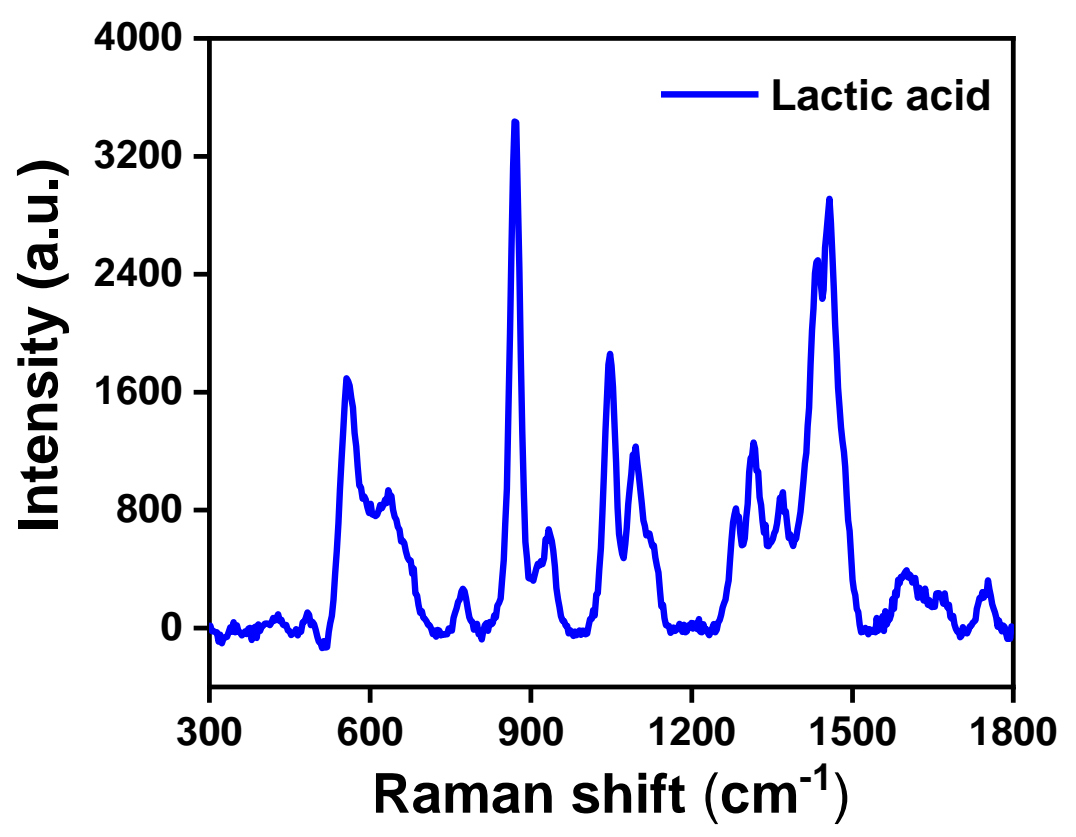

Figure S24. Raman spectrum of lactic acid. 


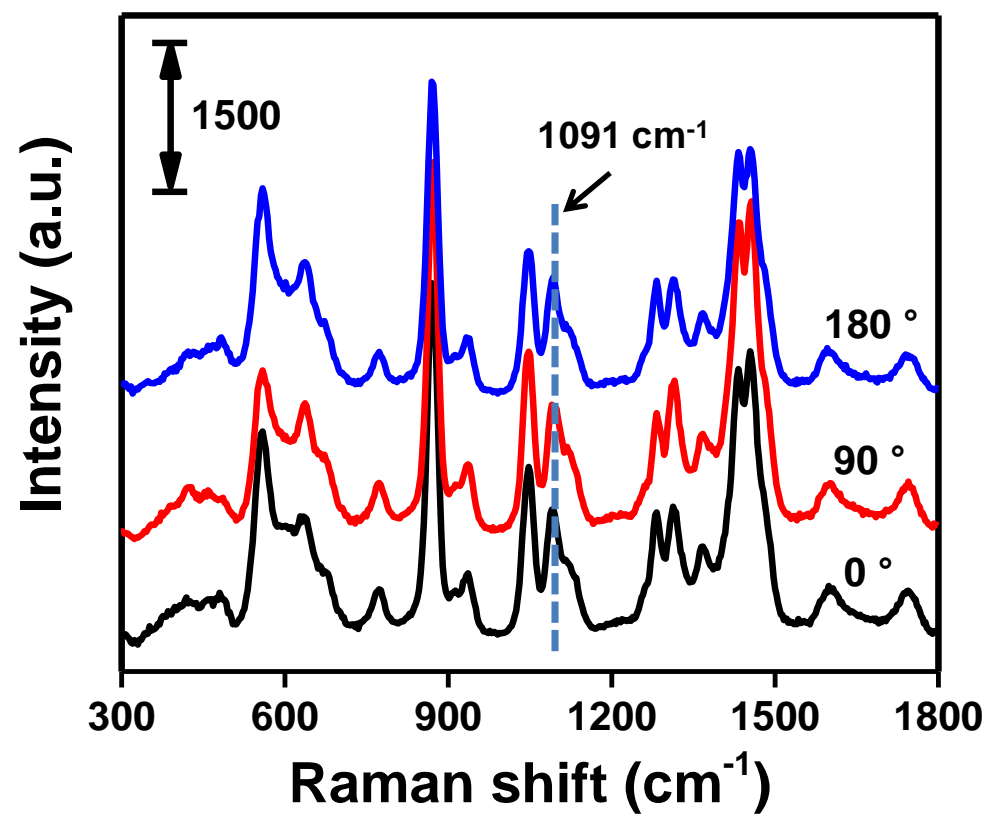

Figure S25. E-SERS spectra of $20 \mathrm{mM}$ lactate under different bending angles.

Table S2. Raman intensity at $1091 \mathrm{~cm}^{-1}$ under different bending angles.

\begin{tabular}{|c|c|c|c|}
\hline Bending Angle & $0^{\circ}$ & $90^{\circ}$ & $180^{\circ}$ \\
\hline $\begin{array}{l}\text { Intensity (a.u.) } \\
\text { (at } 1091 \mathrm{~cm}^{-1} \text { ) }\end{array}$ & 1091.90 & 1082.28 & 1009.13 \\
\hline
\end{tabular}



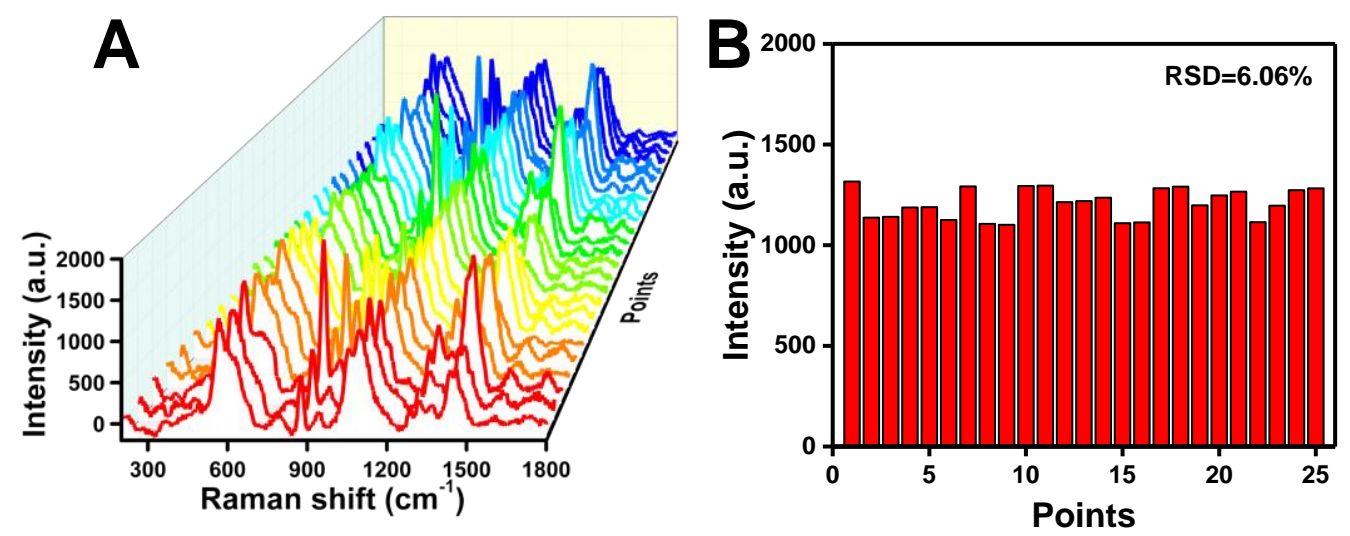

Figure S26. (A) E-SERS spectra of $20 \mathrm{mM}$ lactate and (B) RSD of $\sim 1091 \mathrm{~cm}^{-1}$ peak intensity conveying both intensity and reproducibility of the 25 random points. 


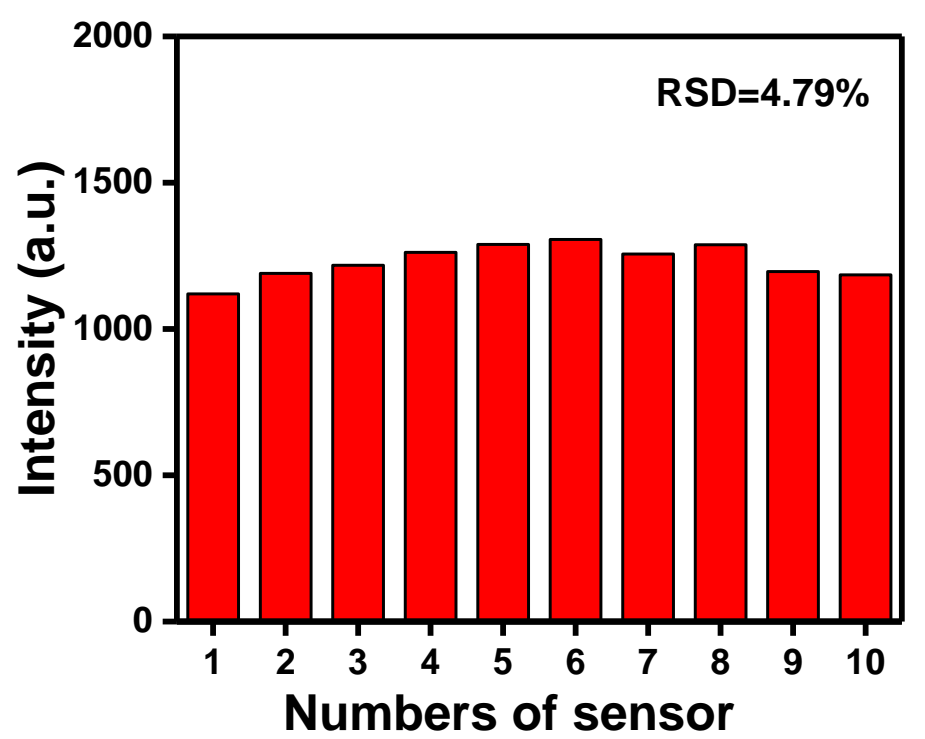

Figure S27. RSD of $\sim 1091 \mathrm{~cm}^{-1}$ peak intensity of $20 \mathrm{mM}$ lactate conveying repeatability of the $\mathrm{Au} / \mathrm{ZnO} \mathrm{NRs}$ based wearable sensors. 

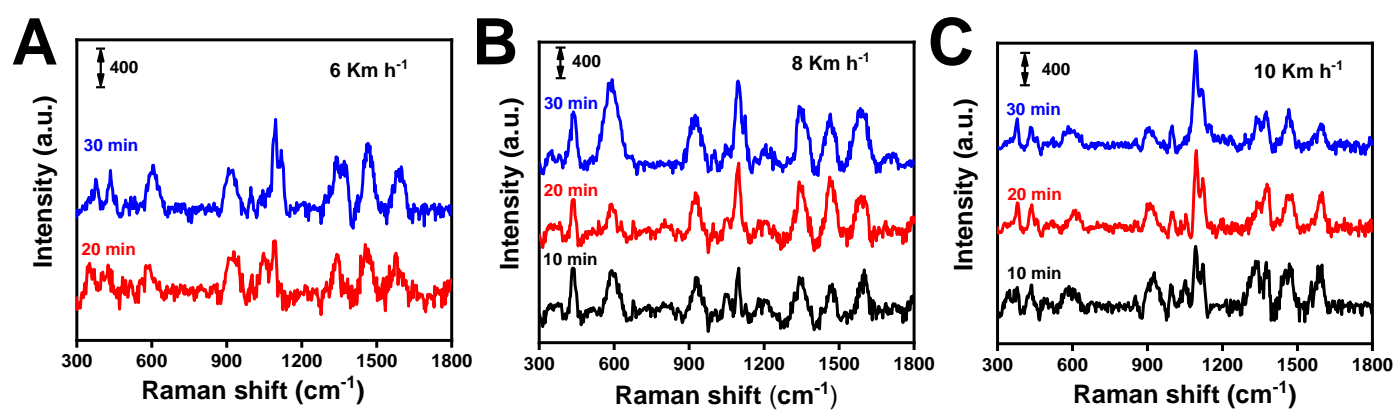

Figure S28. E-SERS spectra of lactate in the sweat of the female volunteer when exercising at different running speeds: (A) $6 \mathrm{~km} \mathrm{~h}^{-1}$, (B) $8 \mathrm{~km} \mathrm{~h}^{-1}$, (C) $10 \mathrm{~km} \mathrm{~h}^{-1}$. 

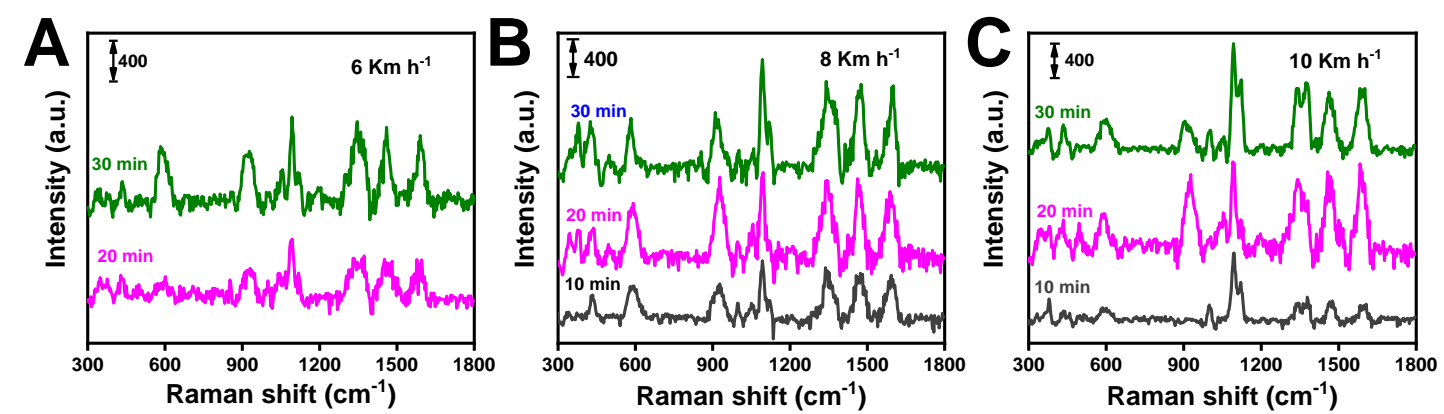

Figure S29. E-SERS spectra of lactate in the sweat of the male volunteer when exercising at different running speeds: (A) $6 \mathrm{~km} \mathrm{~h}^{-1}$, (B) $8 \mathrm{~km} \mathrm{~h}^{-1}$, (C) $10 \mathrm{~km} \mathrm{~h}^{-1}$. 


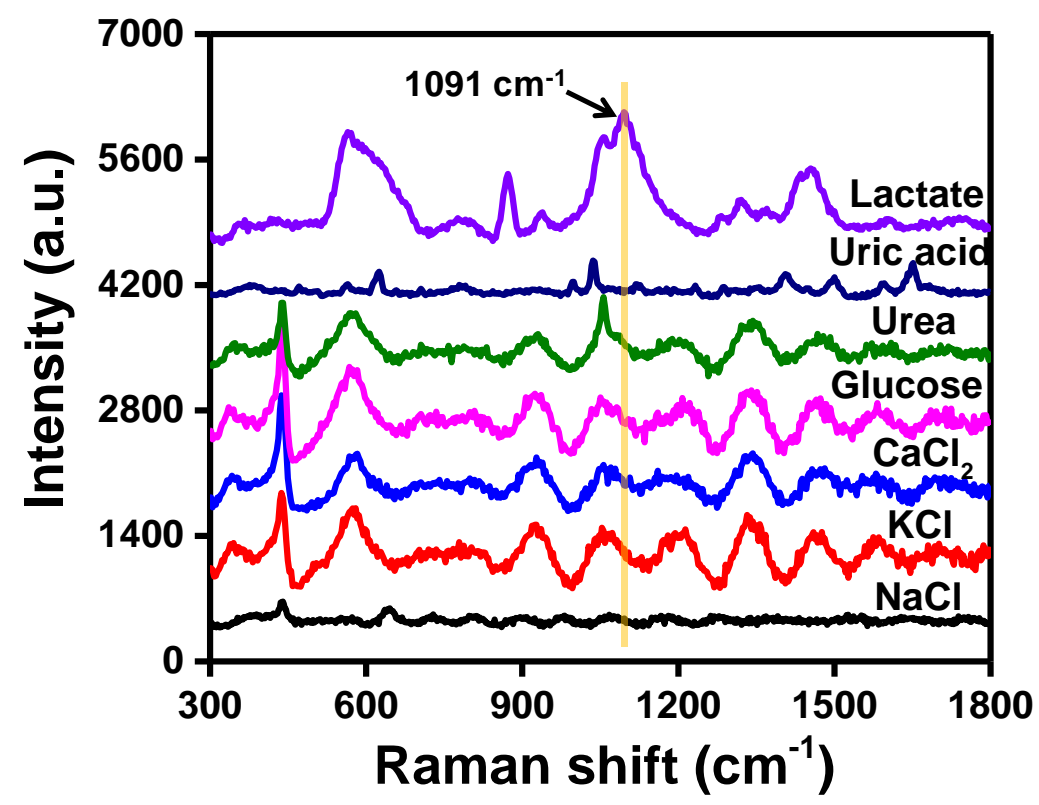

Figure S30. E-SERS spectra of $\mathrm{NaCl}(10 \mathrm{mM}), \mathrm{KCl}(5 \mathrm{mM}), \mathrm{CaCl}_{2}(0.5 \mathrm{mM})$, glucose $(40 \mu \mathrm{M})$, urea $(2 \mathrm{mM})$, uric acid $(2 \mathrm{mM})$, lactate $(20 \mathrm{mM})$ in sweat. 


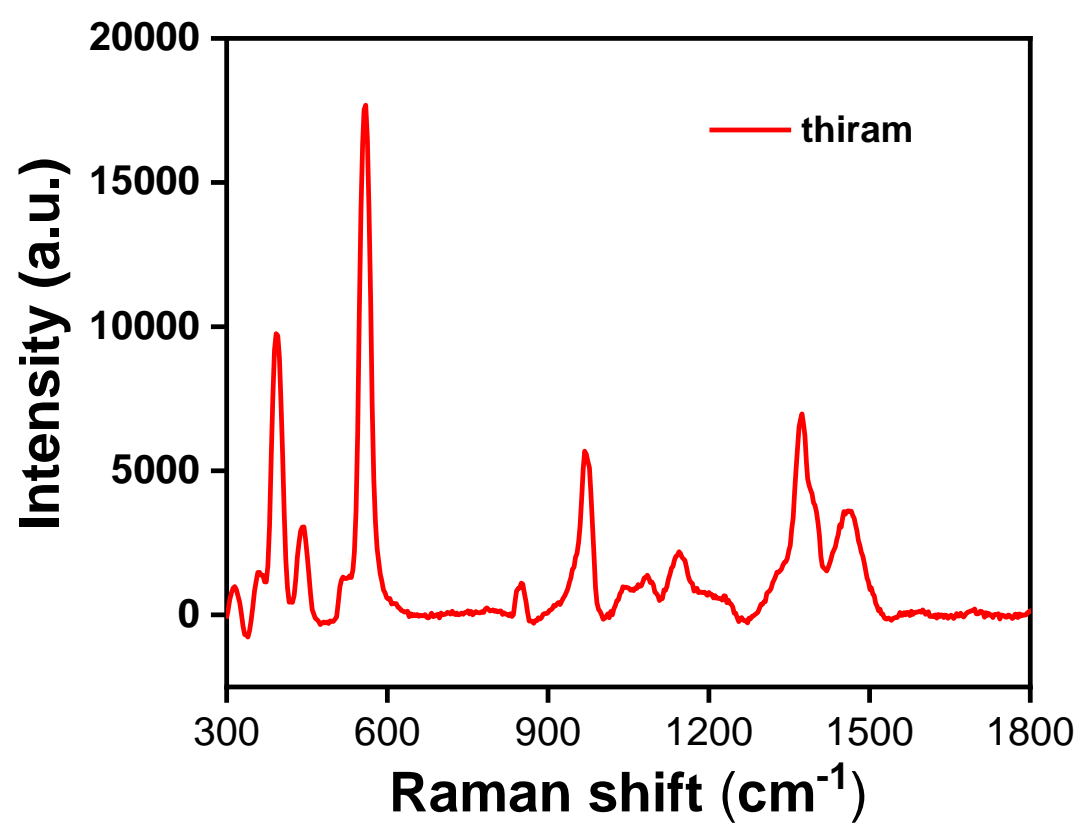

Figure S31. Raman spectrum of thiram. 

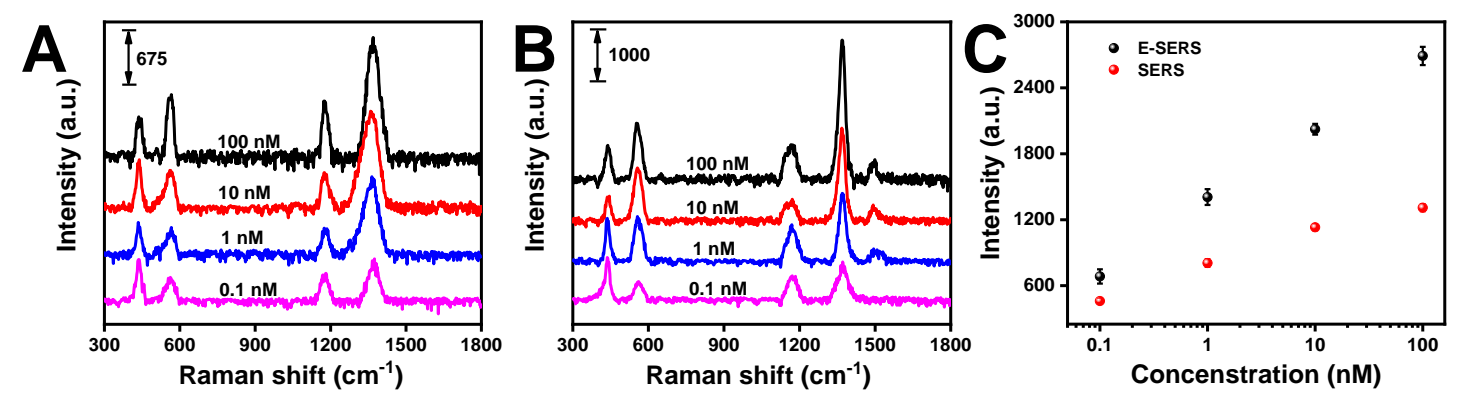

Figure S32. (A) SERS spectra of thiram at different concentrations. (B) E-SERS spectra of thiram at different concentrations. (C) Linear calibration plot of thiram concentration and signal intensity at $1375 \mathrm{~cm}^{-1}$ in the Raman spectra of SERS and E-SERS. 


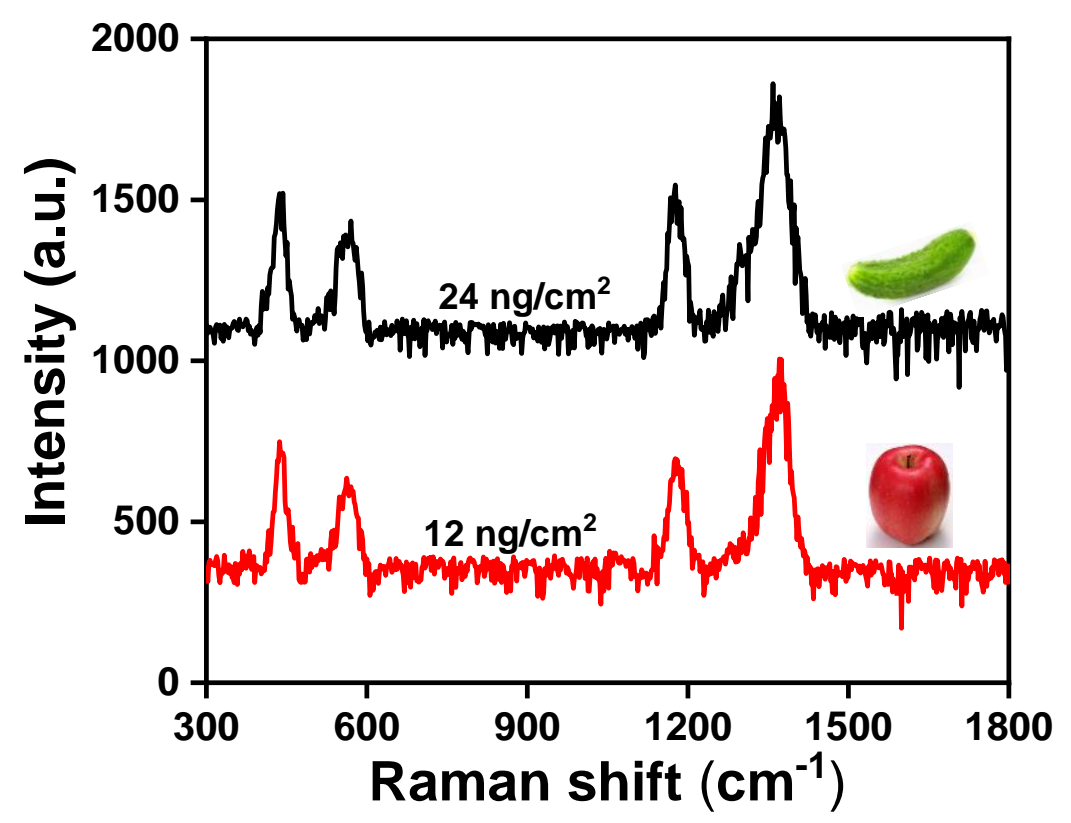

Figure S33. E-SERS spectra of thiram extracted from the surfaces of apples and cucumbers using the as-proposed flexible substrate. 


\section{REFERENCES}

(1) Li, H.; Dai, H.; Zhang, Y.; Tong, W.; Gao, H.; An, Q. Surface-Enhanced Raman Spectra Promoted by a Finger Press in an All-Solid-State Flexible Energy Conversion and Storage Film. Angew. Chem. Int. Ed. 2017, 56, 1-7.

(2) Li, H.; Dai, H.; Zhang, Y.; Lee, Y. H.; Koh, C. S. L.; Phan-Quang, G. C.; Tong, W.; Zhang, Y.; Gao, H.;Ling, X. An, Q. Triboelectrically Boosted SERS on Sea-Urchin-Like Gold Clusters Facilitated by a High Dielectric Substrate. Nano Energy 2019, 64, 103959.

(3) Almohammed, S.; Fularz, A.; Zhang, F.; Alvarez-Ruiz, D.; Bello, F.; O’Regan, D.

D.; Rodriguez, B.J.; Rice, J. H. Flexing Piezoelectric Diphenylalanine-Plasmonic Metal Nanocomposites to Increase SERS Signal Strength. ACS Appl. Mater. Interfaces 2020, 12, 48874-48881.

(4) Choi, M.-Y.; Choi, D.; Jin, M.-J.; Kim, I.; Kim, S.-H.; Choi, J.-Y.; Lee, S. Y.; Kim, J. M.; Kim, S.-W. Mechanically Powered Transparent Flexible Charge-Generating Nanodevices with Piezoelectric ZnO Nanorods. Adv. Mater. 2009, 21, 2185-2189. 